\begin{tabular}{|c|c|c|}
\hline & JSI 9 (1) (2020) & I \\
\hline IIS & Jurnal Sastra Indonesia & 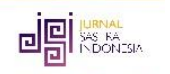 \\
\hline UNNES & http://journal.unnes.ac.id/sju/index.php/jsi & 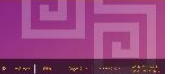 \\
\hline
\end{tabular}

\title{
KESANTUNAN BERBAHASA DALAM TUTURAN FILM MY STUPID BOSS 1
}

\section{Inayah Wulansafitri ${ }^{\bowtie 1}$ dan Ahmad Syaifudin ${ }^{2}$}

Program Studi Sastra Indonesia, Jurusan Bahasa dan Sastra Indonesia, Fakultas Bahasa dan Seni, Universitas Negeri Semarang, Indonesia

\begin{tabular}{|c|c|}
\hline Info Artikel & Abstrak \\
\hline $\begin{array}{l}\text { Sejarah Artikel: } \\
\text { Diterima Agustus } 2019 \\
\text { Disetujui Januari } 2020 \\
\text { Dipublikasikan Maret } 2020\end{array}$ & $\begin{array}{l}\text { Kesantunan berbahasa dibutuhkan untuk menjaga hubungan sosial dalam } \\
\text { bermasyarakat. Perlu adanya media dalam membimbing masyarakat agar bisa menjadi } \\
\text { santun, salah satunya dengan film. Film selain berfungsi sebagai tontonan juga bisa } \\
\text { sebagai tuntunan. My Stupid Boss } 1 \text { adalah Film terlaris ketiga di Indonesia dengan } 3 \\
\text { juta penonton pada tahun } 2016 \text {. Sebagai film yang masih sering diputar di layar televisi, } \\
\text { mungkin saja terdapat pelanggaran dalam tuturan film tersebut. Penelitian ini bertujuan } \\
\text { untuk menjelaskan bentuk pematuhan dan pelanggaran kesantunan, serta implikatur } \\
\text { yang timbul akibat pelanggaran kesantunan pada tuturan film My Stupid Boss } 1 . \\
\text { Pendekatan penelitian ini berupa pendekatan pragmatik dan pendekatan deskriptif } \\
\text { kualitatif. Data penelitian ini berupa penggalan tuturan yang diduga terdapat } \\
\text { pematuhan dan pelanggaran kesantunan berbahasa. Sumber data dalam penelitian ini } \\
\text { yaitu keseluruhan tuturan di dalam film. Teknik pengumpulan data menggunakan } \\
\text { teknik simak bebas libat cakap dan teknik catat. Metode analisis data berupa metode } \\
\text { padan, sedangkan metode penyajian hasil analisis data menggunakan metode informal. } \\
\text { Dari } 57 \text { data, terdapat } 19 \text { data mematuhi pematuhan prinsip kesantunan, } 38 \text { data } \\
\text { melanggar prinsip kesantunan, dan } 15 \text { implikatur yang muncul. Dari penelitian ini } \\
\text { diharapkan dapat menemukan makna dalam sebuah film yang akan berguna dengan } \\
\text { referensi dalam kehidupan. }\end{array}$ \\
\hline
\end{tabular}

\begin{abstract}
Language politeness is needed to maintain social relations in society. Media is needed to guide the public so they can be polite, one of them is with film. Besides functioning as a movie, it can also be a guide. My Stupid Boss 1 is the third best-selling film in Indonesia with 3 million viewers in 2016. As a film that is still often played on television screens, there may be violations in the film's speech. This study aims to explain the form of obedience and violation of politeness, as well as the implications arising from politeness violations in the movie My Stupid Boss 1. This research approach is a pragmatic approach and a qualitative descriptive approach. The data of this research are in the form of speech fragments which are suspected to have a violation and politeness violation. The source of data in this study is the whole utterance in the film. Data collection techniques using the technique of free and involved in proficiency and note taking techniques. The data analysis method is in the form of a matching method, while the method of presenting the results of data analysis uses the informal method. From 57 data, there are 19 data that obey the politeness principle, 38 data violate politeness principle, and 15 implicatures that appear. From this research it is expected to find meaning in a film that will be useful with references in life.
\end{abstract}

(C) 2020 Universitas Negeri Semarang

$\begin{array}{lr}\text { Alamat korespondensi: } & \text { ISSN 2252-6315 } \\ \text { Gedung B1 Lantai 1 FBS Unnes } & \text { E-ISSN 2685-9599 } \\ \text { Kampus Sekaran, Gunungpati, Semarang, 50229 } & \\ \text { E-mail: xiiak319inayahwulansafitri@ mail.unnes.ac.id } & \end{array}$




\section{PENDAHULUAN}

Kesantunan berbahasa dibutuhkan untuk menjaga hubungan sosial. Tuturan dalam bahasa Indonesia secara umum sudah dianggap santun jika penutur menggunakan kata-kata yang santun, tuturannya tidak mengandung ejekan secara langsung, tidak memerintah secara langsung, serta menghormati orang lain (Anam, 2011:1). Melalui film masyarakat bisa dituntun untuk bersikap santun. My Stupid Boss 1 adalah film terlaris ketiga di Indonesia dengan 3 juta penonton yang juga berhasil meraih Piala Citra di Festival Film Indonesia 2006 untuk kategori Sutradara Terbaik, Pemeran Utama Pria Terbaik, Pemeran Pendukung Pria Terbaik, Penyunting Gambar Terbaik, Pengarah Artistik Terbaik, Perancang Busana Terbaik, dan Penulis Skenario Adaptasi Terbaik (Resmardi, Nurati, \& Siswanto, 2018:5). Meski banyak mendapat penghargaan, film ini tidak luput dari masalah kesantunan. Hal ini menjadi alasan diadakannya penelitian tentang prinsip kesantunan dalam tuturan film tersebut.

Terdapat penelitian yang relevan dari beberapa peneliti bahasa, antara lain Felemban (2012) mengkaji tentang prinsip percakapan yang hanya difokuskan pada prinsip kesederhanaan pada teks drama The Importance of Being Earnest (1894), Alafnan (2014) mengkaji tentang kesantunan, strategi positif dan negatif yang digunakan pada tenaga kerja PT Email Kantor Malaysia, Nurjamily (2015) mengkaji kesantunan berbahasa Indonesia yang ada di dalam lingkungan keluarga, Primadianti (2015) membahas tentang ketidaksantunan yang disajikan dalam film Paranorman, Etikawati (2015) mengkaji tentang pematuhan dan pelanggaran kesantunan berbahasa, Pertiwi (2016) menganalisis kesantunan berbahasa dalam film Alangkah Lucunya (Negeri Ini) karya Deddy Mizwar dan implikasinya terhadap pembelajaran bahasa dan sastra Indonesia di SMA, Rohana (2017) mengkaji tentang pematuhan dan pelanggaran kesantunan berbahasa pada siswa SMK Satu Nusa 2 Bandar Lampung, Haryadi dan Setyasih (2017) membahas tentang pelanggaran dan pematuhan bidal-bidal prinsip kesantunan yang ada di lirik lagu Iwan Fals, Hartiningrum dan Sulistiyono (2017) mengidentifikasikan bentuk-bentuk penyimpangan kesantunan berbahasa dalam teks pengumuman karya siswa kelas VII SMP Muhammadiyah 4, Cahyani (2017) membahas tentang kesantunan berbahasa mahasiswa dalam berinteraksi di lingkungan Universitas Tidar, Rahardi (2017) membahas manifestasi pragmatis dari ketidaksopanan linguistik, adapun
Imbowati, Mardikantoro, dan Indiatmoko (2018) menganalisis pelanggaran kesantunan pada tuturan penyiar radio Erte $F M$ Temanggung, Faridah (2018) mendeskripsikan pelanggaran prinsip kesantunan dalam sastra lisan madihin, Duong Bach Nhat (2018) membahas strategi positif yang digunakan dalam mengundang dan menolak undangan oleh orangorang Vietnam, Putri (2018) membahas tentang penyimpangan maksim kesantunan pada film kartun spongebob squarepants karya Stephen Hillenburg (kajian pragmatik), Wakaimbang, dkk. (2018) membahas tentang kesantunan berbahasa dalam grup facebook dan implikasinya terhadap pembelajaran bahasa Indonesia, dan Suryani (2019) membahas tentang realisasi tindak kesantunan berbahasa dalam film Dilan 1990 sebagai bentuk karakter pendidikan: kajian pragmatik.

Dari beberapa penelitian tersebut, terdapat persamaan dan perbedaan terhadap penelitian yang dilakukan. Persamaan yang banyak dijumpai adalah fokus penelitian. Semua penelitian meneliti tentang kesantunan berbahasa. Meski begitu, teori-teori yang digunakan tidaklah sama. Peneliti di sini menggunakan teori prinsip kesantunan dari Leech (2014). Leech (2014) mengelompokkan prinsip kesantunan menjadi sepuluh bidal, yaitu Bidal Kemurahhatian (Generosity Maxim), Bidal Ketimbangrasaan (Tact Maxim), Bidal Keperkenaan (Approbation Maxim), Bidal Kerendahhatian (Modesty Maxim), Bidal Kewajiban S ke O (Obligation of $S$ to $O$ Maxim), Bidal Kewajiban O ke S (Obligation Of $O$ To $S$ Maxim), Bidal Kesetujuan (Agreement Maxim), Bidal Sikap Diam atas Pendapat (OpinionReticence Maxim), Bidal Kesimpatian (Sympathy Maxim), Bidal Merasa Diam (Feeling-Reticence Maxim).

Beberapa penelitian terdahulu belum ada yang menggunakan teori ini. Penelitian ini diharapkan dapat melengkapi hasil-hasil penelitian tentang pragmatik khususnya dalam hal kesantunan berbahasa.

Tujuan dari penelitian ini adalah menjelaskan bentuk pematuhan dan pelanggaran kesantunan, serta implikatur dari pelanggaran kesantunan dalam tuturan film My Stupid Boss 1. Manfaat penelitian ini adalah untuk menyumbangkan pengetahuan dalam bidang pragmatik khususnya dalam prinsip kesantunan berbahasa sehingga ilmu pragmatik semakin berkembang. Selain itu agar masyarakat dapat mengetahui dan memahami kesantunan yang ada pada tuturan film My Stupid Boss 1 . 


\section{METODE PENELITIAN}

Pendekatan yang digunakan dalam penelitian ini meliputi dua pendekatan, yaitu pendekatan teoretis dan metodologis. Secara teoretis, pendekatan yang digunakan dalam penelitian ini adalah pendekatan pragmatik. Secara metodologis yang digunakan dalam penelitian ini adalah pendekatan deskriptif kualitatif. Data penelitian ini berupa penggalan tuturan yang diduga terdapat pematuhan dan pelanggaran kesantunan berbahasa. Sumber data dalam penelitian ini yaitu keseluruhan tuturan di dalam film My Stupid Boss 1. Metode yang digunakan untuk mengumpulkan data adalah metode simak dengan teknik simak bebas libat cakap dan teknik catat. Metode analisis data yang digunakan dalam penelitian ini adalah metode padan, teknik dasar yang digunakan adalah dengan teknik pilah unsur penentu atau teknik PUP. Adapun alatnya adalah daya pilah yang bersifat mental yang dimiliki oleh peneliti. Dalam penelitian ini teknik yang digunakan dalam penyajian hasil analisis adalah teknik penyajian secara informal.

\section{HASIL DAN PEMBAHASAN}

Hasil penelitian ini mencakup tiga hal yang sesuai dengan rumusan masalah dan tujuan penelitian yang dibahas, yaitu (1) bidal-bidal kesantunan yang dipatuhi dalam tuturan film $M y$ Stupid Boss 1, (2) bidal-bidal kesantunan yang dilanggar dalam tuturan film My Stupid Boss 1, (3) implikatur yang timbul akibat adanya pelanggaran kesantunan dalam tuturan film $M y$ Stupid Boss 1. Dalam analisis ini ditemukan 57 data, 19 data mematuhi pematuhan prinsip kesantunan dan 38 data melanggar prinsip kesantunan, serta terdapat 15 implikatur yang muncul akibat pelanggaran kesantunan.

Bentuk Pematuhan Prinsip Kesantunan dalam Tuturan film My Stupid Boss 1

Dari 10 bidal kesantunan milik Leech hanya 9 bidal yang dipatuhi pada tuturan film $M y$ Stupid Boss 1. Hasil penelitian menunjukkan adanya 19 data yang mematuhi bidal kesantunan. 19 data tersebut terdiri atas 1 data mematuhi bidal kemurahhatian (generosity maxim), 1 data mematuhi bidal ketimbangrasaan (tact maxim), 1 data mematuhi bidal keperkenaan (approbation maxim), 9 data mematuhi bidal kewajiban $\mathrm{S}$ ke O (obligation of $S$ to $O$ maxim), 2 data mematuhi bidal kewajiban $\mathrm{O}$ ke $\mathrm{S}$ (obligation of $O$ to $S$ maxim), 1 data mematuhi bidal kesetujuan (agreement maxim), 1 data mematuhi bidal sikap diam atas pendapat (opinion-reticence maxim), 2 data mematuhi bidal kesimpatian (sympathy maxim), dan 1 data mematuhi bidal merasa diam (feeling-reticence maxim). Dalam pematuhan ditemukan hal baru pada bidal kewajiban S ke O.

\section{Bidal Kewajiban $\mathrm{S}$ ke $\mathrm{O}$ (Obligation of $S$ to $O$ Maxim)}

Bidal kewajiban S kepada O berisi tindak tutur santun yang memberikan perhatian tinggi pada kesalahan dan kewajiban S kepada O. Misalnya meminta maaf atas kesalahan, mengucapkan terima kasih atas pertolongan, dan lain-lain. Menurut Leech (2014) apabila dinyatakan dalam modus yang harus dipatuhi bidal ini akan berbunyi 'berikan nilai tinggi atas kewajiban S terhadap O'. Dari hasil analisis terhadap tuturan film My Stupid Boss 1, ternyata ditemukan pematuhan bidal kewajiban S ke O yang mana kesalahan tidak hanya dimiliki oleh $\mathrm{S} /$ penutur. Kesalahan bisa saja dari mitra tutur, namun demi kesantunan S/mitra tutur tetap memberikan nilai tinggi pada kewajiban atas kesalahan tersebut.

Pematuhan bidal kewajiban S ke O yang mana kesalahan tidak berasal dari S/mitra tutur terdapat pada percakapan brikut.

\section{(1) KONTEKS: PELAYAN TIDAK BISA MENGGUNAKAN KARTU MILIK BOSMAN \\ Tuturan \\ Pelayan : "Umm maaf cik, card cik ni tak boleh pake lah, kena reject." \\ Bosman : "Ha? Who masak si kamu? Lho kenapa si ini?" (Data 30)}

Pada percakapan (1) tersebut terdapat pematuhan prinsip kesantunan bidal kewajiban $\mathrm{S}$ kepada O. Di dalam tuturan tersebut pelayan mematuhi prinsip kesantunan bidal kewajiban S kepada $\mathrm{O}$ Bidal ini berarti memberikan perhatian tinggi pada kesalahan dan kewajiban S kepada O. Tuturan "Umm maaf cik" dituturkan oleh pelayan untuk meminta maaf kepada Bosman mengenai kartu kredit bosman yang memang sudah tidak bisa dipakai. Pelayan tetap meminta maaf kepada bosman dengan menuturkan "Umm maaf cik" meskipun itu bukanlah kesalahannya. Sebagai pelayan yang baik, ia menjaga kesantunannya kepada pelanggan. Pelayan itu memberi perhatian tinggi atas kewajibannya untuk bersikap sopan dan bertutur santun.

Tuturan "Umm maaf cik" yang diucapkan oleh pelayan telah mematuhi modus bidal kewajiban S kepada O yang berbunyi 'berikan nilai tinggi atas kewajiban $S$ terhadap $\mathrm{O}$ '. Pelayan memberikan nilai tinggi atas kewajibannya meminta maaf kepada pelanggan yaitu Bosman karena kartu Bosman yang tidak bisa diakses. Pelayan meminta maaf bukan 
karena dia melakukan kesalahan, namun sebagai pelayan yang baik ia tidak mau menyinggung perasaan pelanggannya dengan mengatakan secara langsung bahwa kartunya sudah tidak bisa digunakan. Dari uraian di atas pelayan tersebut telah mematuhi prinsip kesantunan bidal kewajiban S kepada O. Dari peristiwa ini dapat disimpulkan bahwa meminta maaf tidak selalu dilakukan oleh orang yang melakukan kesalahan. Untuk menjaga perasaan orang lain agar tidak terluka, kadang meminta maaf perlu dilakukan. Hal tersebut termasuk kesantunan karena fungsi dari kesantunan adalah mempertahankan sebuah hubungan yang telah terjalin ataupun yang baru terjalin.

Pematuhan terhadap bidal ini juga terjadi pada percakapan berikut.

(2) KONTEKS: DIANA MENINGGALKAN TEMAN-TEMANNYA YANG SEDANG MENGOBROL KARENA DIANA HARUS BERANGKAT INTERVIEW Tuturan Vivian : "Hey Diana tetap semangat
taw"

Diana

$$
\text { : "Well do, thankyou. }
$$$$
\text { Byee" (Data 03) }
$$

Pada percakapan (2) di atas terdapat pematuhan prinsip kesantunan bidal kewajiban $S$ kepada O. Tuturan Vivian mematuhi prinsip keantunan bidal kewajiban $\mathrm{S}$ kepada $\mathrm{O}$, khususnya dalam hal kewajiban. Tuturan "Hey Diana tetap semangat taw" merupakan tuturan direktif yang bersifat menyuruh. Dalam peristiwa tutur tersebut Vivian merupakan teman sekaligus tetangga Diana. Sebagai teman dan tetangga yang baik, Vivian menyuruh Diana agar semangat dalam melakukan interview. Tuturan tersebut menunjukkan adanya perhatian tinggi dari penutur kepada mitra tutur.

Tuturan "Hey Diana tetap semangat taw" telah mematuhi modus dari bidal kewajiban S kepada $\mathrm{O}$ yang berbunyi 'berikan nilai tinggi atas kewajiban S terhadap O'. Nilai tinggi dari kewajiban yang diberikan Vivian kepada Diana adalah semangat. Vivian memberikan perhatian tinggi berupa semangat kepada Diana. Dari uraian di atas dapat disimpulkan bahwa tuturan Vivian mematuhi prinsip kesantunan bidal kewajiban S kepada O.

Bentuk Pelanggaran Prinsip Kesantunan dalam Tuturan film My Stupid Boss 1

Terdapat 8 bidal yang dilanggar pada tuturan film My Stupid Boss 1. Hasil penelitian menunjukkan adanya 38 data yang melanggar bidal kesantunan. 38 data tersebut terdiri atas 7 data melanggar bidal kemurahhatian (generosity maxim), 6 data melanggar bidal ketimbangrasaan (tact maxim), 12 data melanggar bidal keperkenaan (approbation maxim), 6 data melanggar bidal kerendahhatian (modesty maxim), 2 data melanggar bidal kesetujuan (agreement maxim), 2 data melanggar bidal sikap diam atas pendapat (opinion-reticence maxim), 1 data melanggar bidal kesimpatian (sympathy maxim), dan 2 data melanggar bidal merasa diam (feelingreticence maxim).

Dari hasil analisis terhadap tuturan film My Stupid Boss 1, ditemukan hal baru pada pelanggaran terhadap bidal keperkenaan. Dalam bidal ini tidak hanya pemberian nilai tinggi pada kualitas $\mathrm{O}$, tetapi juga kualitas yang terkait dengan $\mathrm{O}$, entah itu teman, kekasih, saudara atau lainnya. Terlihat pada percakapan berikut

(3) KONTEKS: DIANA MENGELUH DI HADAPAN DIKA TENTANG SIKAP BOSMAN

Tuturan

Kerani : "Temen kamu tu ya si kumis lele buntelan karung pala botak rambut suir suir, aku yakin gak ada lagi tuh manusia kayak dia. Aku rasa otaknya dia itu cuma segaris persis kayak kumisnya! kayak kumisnya!"

Dika : "Dia emang gitu orangnya" (Data 32)

Pada percakapan (3) di atas terdapat pelanggaran prinsip kesantunan bidal keperkenaan. Dalam tuturan tersebut, Diana telah melakukan pelanggaran bidal keperkenaan dengan menuturkan tuturan "Temen kamu tu ya si kumis lele buntelan karung pala botak rambut suir suir, aku yakin gak ada lagi tuh manusia kayak dia. Aku rasa otaknya dia itu cuma segaris persis kayak kumisnya". Dalam peristiwa tersebut Diana sedang kesal dengan Bossman dan mengungkapkan kekesalannya di hadapan Dika suaminya. Diana mengatai Bossman dengan sebutan kumis lele, buntelan karung, kepala botak, dan rambutnya yang suir suir. Bahkan Diana mengatakan Bossman otaknya cuma segaris. Tuturan Diana tersebut merendahkan kualitas Bossman. Meski kritikan tersebut tidak ditujukan kepada mitra tutur yaitu Dika, namun kritikan tersebut berkaitan dengan Dika. Bossman adalah teman dari Dika dan kritikan dari Diana dapat membuat Dika sakit hati. Pada umumnya orang tidak suka jika ada orang lain yang mencela temannya sendiri.

Tuturan "Temen kamu tu ya si kumis lele buntelan karung pala botak rambut suir suir, aku yakin gak ada lagi tuh manusia kayak dia. Aku rasa 
otaknya dia itu cuna segaris persis kayak kumisnya tidak mematuhi modus bidal keperkenaan yang berbunyi 'berikan nilai tinggi pada kualitas O'. Bossman memang tidak memberikan nilai tinggi pada kualitas O/ mitra tutur yaitu Dika. Diana juga tidak memberikan nilai rendah pada kualitas Dika, namun Diana memberikan nilai rendah pada orang yang berkaitan dengan mitra tutur yaitu Dika. Hal tersebut bisa saja menyebabkan rusaknya hubungan yang akan atau sudah dibangun, sedangkan fungsi kesantunan sendiri adalah mempertahankan sebuah hubungan. Dari uraian tersebut dapat disimpulkan bahwa tuturan Diana telah melanggar prinsip kesantunan bidal keperkenaan.

Pelanggaran terhadap bidal ini juga ditemukan pada percakapan berikut.

(4) KONTEKS: DI DALAM RUANGAN BOSSMAN, DIANA BERANJAK PERGI SETELAH MENDENGAR PENJELASAN DARI BOSSMAN MENGENAI PEKERJAAN YANG DIA DAPATKAN

Tuturan

Bosman

: "Buru-buru amat sih. Tunggu dulu dong. (berdiri) kamu tahu nggak? Saya itu tiga belas tahun tinggal di California. Kamu tahu California di mana nggak? (menarik peta dan menuding) Amerika hehehehe. Dulu ya, di California tu saya pertama kali ketemu sama Dika. Kamu kalo liat suami dulu, ya ampun. Katrok banget. Norak."

Pada percakapan (4) di atas terdapat pelanggaran prinsip kesantunan bidal keperkenaan. Dalam tuturan tersebut, Bossman telah melakukan pelanggaran bidal keperkenaan dengan menuturkan tuturan "Kamu kalo liat suami dulu, ya ampun. Katrok banget. Norak". Bossman saat melakukan interview terhadap Diana justru mengkritik Dika yang merupakan suami Diana dengan kritikan bahwa Dika katrok dan norak. Meski kritikan tersebut tidak ditujukan kepada mitra tutur, namun kritikan tersebut berkaitan dengan mitra tutur. Dika adalah suami dari Diana dan kritikan dari Bossman akan membuat Diana sakit hati. Pada umumnya orang tidak suka jika ada orang lain yang mencela pasangannya. Tuturan "Kamu kalo liat suami dulu, ya ampun. Katrok banget. Norak" tidak mematuhi modus bidal keperkenaan yang berbunyi 'berikan nilai tinggi pada kualitas $\mathrm{O}$ '. Bossman memang tidak memberikan nilai tinggi pada kualitas O. Bossman juga tidak memberikan nilai rendah pada kualitas $\mathrm{O}$, namun Bossman memberikan nilai rendah pada orang yang berkaitan dengan $\mathrm{O}$. Hal tersebut bisa saja menyebabkan rusaknya hubungan yang akan atau sudah dibangun, sedangkan fungsi kesantunan sendiri adalah mempertahankan sebuah hubungan. Dari uraian tersebut dapat disimpulkan bahwa tuturan Bossman telah melanggar prinsip kesantunan bidal keperkenaan. Implikatur yang Timbul akibat Pelanggaran Kesantunan dalam Tuturan Film My Stupid Boss 1

Berdasarkan pelanggaran prinsip kesantunan yang telah ditemukan dalam analisis tuturan film My Stupid Boss 1, terdapat 15 implikatur yang ditemukan. 15 implikatur tersebut adalah menyindir, tidak mau rugi, menghina, mengejek, menyombongkan diri, mempermainkan, meremehkan, merasa kesal, mencari keuntungan, meminta sesuatu, memaksakan, menyepelekan sesuatu, menyembunyikan sesuatu, menolak sesuatu, dan menuduh.

Implikatur yang paling banyak ditemukan pada tuturan film My Stupid Boss 1 adalah implikatur mengejek. Contoh percakapan yang terdapat implikatur mengejek:

(5) KONTEKS: MR. KOH MEMBERITAHU BOSSMAN BAHWA AC DI RUANG KERJA TIDAK BISA DIPERBBAIKI KARENA SUDAH TUA

Tuturan

Mr koh : "Can not be fix. It is too old."

Bossman : "Oh tua, setua Mr. Koh ya.. o ya ya ya ya ya ya (meninggalkan Mr. Koh)" (Data 19)

Pada percakapan (5) di atas terdapat tuturan yang memiliki implikatur 'mengejek'. Hal tersebut dapat dilihat dari tuturan Bossman "Oh tua, setua Mr. Koh ya." Tuturan tersebut telah melanggar prinsip kesantunan bidal keperkenaan (Approbation Maxim) karena merendahkan kualitas $\mathrm{O} /$ mitra tutur. Tuturan Bossman tersebut merupakan tuturan deklarasi karena menyatakan sesuatu.

Dalam peristiwa tutur tersebut Bossman membalas tuturan Mr. Koh yang mengatakan AC sudah tua dan tidak bisa diperbaiki. Bossman menyatakan bahwa AC itu tua setua Mr. Koh. Tuturan tersebut memang seperti Bossman memberitahukan bahwa umur AC tua seperti umur Mr. Koh, namun ada maksud lain di balik tuturan tersebut. Bossman mencoba mengejek Mr. Koh dengan tuturannya. Bossman mengejek Mr. Koh yang sudah tua seperti AC. AC yang sudah tua tersebut tidak bisa diperbaiki. Sama 
halnya dengan Mr.Koh yang semakin tua semakin tidak bisa diperbaiki. Bossman menyamakan Mr. Koh dengan AC yang merupakan benda mati. Tuturan tersebut bisa menjadi sebuah olokan terhadap Mr. Koh.

Implikatur mengejek lainnya ditemukan pada percakapan berikut.

(6) KONTEKS: BOSSMAN DAN DIANA SEDANG BERADA DI DALAM RUANGAN UNTUK INTERVIEW

Tuturan :

Bossman : "Maaf lo ya, ini saya benerbener lupa ini. Aduh... kan biasanya Saya itu kan biasa ketemu orang-orang yang penting. Ya, bukannya kamu ga penting. Tapi yang saya ingat kadang-kadang yang penting-penting aja. Dulu itu saya ingat lo, Dika itu pernah ngasih liat foto kamu sama saya, tapi dulu kamu itu gembrot. banget. Makanya saya pangling. Heheheh" (Data 06)

Pada percakapan (6) di atas terdapat tuturan yang memiliki implkatur 'mengejek'. Tuturan tersebut telah melanggar prinsip kesantunan bidal keperkenaan (Approbation Maxim) karena merendahkan kualitas O/ mitra tutur. Tuturan Bossman tersebut merupakan tuturan deklarasi karena menyatakan sesuatu.

Dalam peristiwa tutur tersebut Bossman sedang melakukan interview terhadap Diana yang akan menjadi karyawan di tempat kerjanya. Bossman baru saja bertemu dengan Diana, Diana sendiri adalah istri Dika yang merupakan sahabat dari Bossman. Saat berbicara dengan Diana, Bossman menuturkan tuturan tapi dulu kamu itu gembrot.. banget. Makanya saya pangling. Tuturan Bossman tersebut terlihat memberitahu Diana bahwa dia dulu berbadan gemuk, namun ada maksud di balik tuturan tersebut. Bossman bermaksud mengejek Diana yang pernah gembrot. Dengan menuturkan bahwa Bossman pangling melihat Diana mengimplikasikan bahwa terdapat banyak perubahan pada tubuh Diana. Hal tersebut dapat menjadi ejekan kepada Diana. Apalagi di dalam peristiwa tutur tersebut Diana ingin diinterview bukan ingin ditertawakan. Meskipun Bossman adalah seorang bos, hal tersebut kurang pantas dituturkan kepada calon karyawan barunya.

\section{PENUTUP \\ Simpulan}

Dalam penelitian ini bidal yang paling banyak dipatuhi adalah bidal kewajiban S ke O (obligation of $S$ to $O$ maxim). Dari hasil analisis ini pada bidal kewajiban $\mathrm{S}$ ke $\mathrm{O}$ (obligation of $S$ to $O$ maxim) ternyata tidak hanya terjadi pada keadaan wajib meminta maaf atas kesalahan diri sendiri, ditemukan data yang menunjukkan kesantunan meminta maaf atas kesalahan yang tidak diperbuat. Bidal yang paling banyak dilanggar adalah bidal keperkenaan (approbation maxim). Dapat dikatakan bahwa sebagian besar tuturan dalam film ini memberikan nilai rendah pada orang lain Pada bidal ini ternyata tidak seutuhnya selalu bermodus 'berikan nilai tinggi pada kualitas O', karena dalam penelitian ini ditemukan pelanggaran lain. Pelanggaran terjadi karena adanya pemberian nilai rendah pada kualitas orang yang berkaitan dengan $\mathrm{O} /$ mitra tutur.

\section{DAFTAR PUSTAKA}

Alafnan, M.A. (2014). Interethnic workplace communication: An investigation into politeness strategies. International Conference on e-Education, e-Business and Information Management (ICEEIM 2014), 208-211. DOI: 10.2991/iceeim-14.2014.61. Diunduh dari https://www.atlantispress.com/proceedings/iceeim-14/11677.

Anam, A. (2011). Kesantunan Berbahasa dalam Buku Ajar Bahasa Indonesia Tataran Unggul: untuk SMK dan MAK Kelas XII Karangan Yustinah dan Ahmad Iskak. Skripsi. Universitas Yogyakarta.

Cahyani, Desy Nur dan Fathur Rokhman. (2017). Kesantunan Berbahasa Mahasiswa dalam Berinteraksi di Lingkungan Universitas Tidar: Kajian Sosiopragmatik. Jurnal Seloka: Jurnal Pendidikan Bahasa dan Sastra Indonesia.Vol. 6 No. 1.

Etikawati, Dina. (2015). Kesantunan Tuturan Antartokoh dalam Novel Namaku Mata Hari Karya Remy Sylado. Jurnal Sastra Indonesia. Vol. 4 No. 1.

Faridah, S. (2018). Pelanggaran Prinsip Kesantunan dalam Sastra Lisan Madihin. Jurnal Kredo, 1(2), 36-52. Diunduh dari https://jurnal.umk.ac.id.

Felemban, F.H. (2012). Building up Learners' Communicative Competence: the Politeness Principle. Procedia - Social and Behavioral Sciences 46(2012), 70-76. Diunduh dari https://www.sciencedirect.com/.

Hartiningrum, W., dan Sulistyono, Y. (2017). Penyimpangan Prinsip Kesantunan pada Teks Pengumuman Karya Siswa Kelas VII SMP Muhammadiyah 4 Sambi Tahun Ajaran 2015/2016: Tinjauan Pragmatik. Jurnal Penelitian Humaniora, 18(2), 95-104. Diunduh dari 
http://journals.ums.ac.id/index.php/humaniora/ article/view/5195.

Haryadi, dan Setyasih, M. (2017). Prinsip Kesantunan Dalam Lirik Lagu Iwan Fals. Jurnal Sastra Indonesia, 6(3), 25-32. Diunduh dari http://journal.unnes.ac.id/sju/index.php/jsi

Imbowati, D.I., Mardikantoro, H.B., dan Indiatmoko, B. (2018). Kesantunan Tuturan Penyiar Radio Erte FM Temanggung. Jurnal Lingua, XIV(2), 126-138. Diunduh dari https://journal.unnes.ac.id/nju/index.php/lingua /article/viewFile/15165/7963.

Leech, G. (2014). The Pragmatics of Politeness. United States of America: Oxford University Press

Nurjamily, W.O. (2015). Kesantunan Berbahasa Indonesia dalam Lingkungan Keluarga. Jurnal Humanika, 15(3),-. Diunduh dari http://ojs.uho.ac.id/index.php/HUMANIKA/art icle/view/608.

Pertiwi, Astri. (2016). Analisis Kesantunan Berbahasa dalam Film Alangkah Lucunya (Negeri Ini) Karya Deddy Mizwar dan Implikasinya terhadap Pembelajaran Bahasa dan Sastra Indonesia di SMA. Skripsi. UIN Syarif Hidayatullah Jakarta.

Primadianti, N. (2015). A Pragmatic Analysis Of Impoliteness In Paranorman Movie. Tesis. Universitas Negeri Yogyakarta.

Putri, Shofia Cahyani. (2018). Penyimpangan Maksim Kesantunan pada Film Kartun Spongebob Squarepants Karya Stephen Hillenburg (Kajian Pragmatik). AKSIS Jurnal Pendidikan Bahasa dan Sastra Indonesia. Vol. 2 No.2.

Rahardi, K. (2017). Linguistic Impoliteness in The Sociopragmatic Perspective. Jurnal Humaniora, 29(3), $309-315 . \quad$ Diunduh dari https://jurnal.ugm.ac.id/jurnalhumaniora/article/view/24954.

Resmadi, R.Y., Nurati, D.E., dan Siswanta. (2017). Analisis Semiotika Film My Stupid Boss. EJurnal UNISRI, 1 (1), 1-15. Diunduh dari https://ejurnal.unisri.ac.id.

Rohana. (2017). Kesantunan Berbahasa dalam Berwawancara Siswa SMK Satu Nusa 2 Bandar Lampung. Jurnal Pesona, 3(2), 200-207. Diunduh dari https: / / ejournal.stkipmpringsewulpg.ac.id/index.php/pesona/article/view/449.

Suryani, Dewi. (2019). Realisasi Tindak Kesantunan Berbahasa dalam Film Dilan 1990 sebagai Bentuk Karakter Pendidikan: Kajian Pragmatik. Skripsi. Universitas Muhammadiyah Surakarta.

Wakaimbang, Hendri, dkk. (2016). Kesantunan Berbahasa dalam Grup Facebook dan Implikasinya Terhadap Pembelajaran Bahasa Indonesia. Jurnal Kata (Bahasa, Sastra, dan Pembelajarannya). Prodi Pendidikan Bahasa dan Sastra Indonesia FKIP Universitas Lampung. 